\title{
O IMPACTO NA GERAÇÃO DE ENERGIA E AS PERDAS EM CONDENSADORES DE VAPOR*
}

\section{Resumo}

Jefferson Monteiro Oliveira ${ }^{1}$ Tiago Rodrigues da Silvar ${ }^{2}$ Marcus Roberto Marincek ${ }^{3}$

A eficiência das turbinas a vapor de condensação é diretamente alterada pelo desempenho dos condensadores de superfície e estes últimos são negativamente afetados não somente pela entrada de ar no sistema, mas também por entupimentos e diminuições nos fluxos de água de refrigeração. Entretanto, qualquer uma das fontes de diminuição da eficiência do condensador geram efeitos similares dificultando a distinção entre elas ou a contribuição de cada uma para a queda no desempenho. Então a decisão pela manutenção tem aspectos claramente econômicos. Este artigo apresenta métodos para avaliação das fontes de perda de desempenho em condensadores e suas consequências na geração de energia.

Palavras-chave: Turbogeradores; Condensadores de vapor; Energia; Eficiência.

\section{THE IMPACT IN THE ENERGY GENERATION AND THE LOSSES IN STEAM} SURFACE CONDENSERS

\section{Abstract}

The efficiency of a condensing steam turbine is directly changed by the performance of surface steam condensers and the condensers are negatively affected not only by air into the system, but also by fouling and decreases in the cooling water flows. However, any of the reduction of sources of condenser efficiency generate similar effects making it difficult to distinguish between them and the contribution of each to the drop in performance. So the decision for maintenance is clearly a economic aspects. This paper presents methods for evaluation of performance loss sources in steam surfasse condensers and their consequences for energy generation.

Keywords: Turbogenerators; Steam surface condensers; Energy; Efficiency.

1 Engenheiro Eletricista, Bacharel, Lider Engenharia de Campo, Engenharia de Campo, TGM Serviços, Sertãozinho, São Paulo, Brasil.

2 Engenheiro Mecânico, Bacharel, Engenheiro, Engenharia de Campo, TGM Serviços, Sertãozinho, São Paulo, Brasil.

3 Engenheiro Mecânico, Bacharel, Engenheiro, Engenharia de Turbinas, TGM Turbinas, Sertãozinho, São Paulo, Brasil. 


\section{INTRODUÇÃO}

$\mathrm{Na}$ operação e manutenção das plantas de geração de energia o condensador de superfície para o vapor de escape das turbinas de condensação é virtualmente negligenciado em comparação com outros equipamentos, principalmente os rotativos (turbinas e geradores). As atividades de operação muitas vezes são limitadas a partir e manter o vácuo e à operação das bombas de exportação de condensado e às bombas de circulação de água e as de manutenção apenas à atividades corriqueiras como lubrificação de rolamentos dos motores. Estas falhas na manutenção sempre levam à equívocos na compreensão dos problemas e na definição de prioridades.

Em tempos de alto valor para a energia produzida, qualquer perda em geração de energia não é bem vista. As turbinas de condensação em particular sofrem demasiadamente com a queda de desempenho do sistema de vácuo. Entupimentos na tubulação de água de refrigeração bem como a presença excessiva de grandes quantidades de ar do lado vapor do condensador afetam negativamente 0 coeficiente global de troca térmica e com isto, perde se vácuo. Infelizmente, como as duas falhas tem efeitos similares, a detecção e seleção entre elas é extremamente complicada.

\section{MATERIAIS E MÉTODOS}

A seguir são apresentados os conceitos usados para o desenvolvimento do trabalho.

\subsection{Condensadores de Superfície}

O condensador de superfície é um trocador de calor do tipo casco-tubo que recebe vapor do escape da turbina com titulação entre 8 e 15\%. O vapor é condensado pela transferência de calor dele para a água que circula nos tubos e, para que esta mudança de fase possa ocorrer, a quantidade de calor transferida para a água deve ser no mínimo igual ao calor latente de vaporização à menor temperatura pratica, que é função tanto do título quanto da pressão no condensador. Esta mudança de fase se dá consequentemente no vácuo. Criando vácuo, o condensador de superfície tende a maximizar a eficiência da turbina.

A pressão de operação é determinada pela temperatura e quantidade de água de refrigeração considerando se que os entupimentos no lado da água de refrigeração e vazamentos de não condensáveis no lado vapor são mínimos. Portanto, isto significa que o coeficiente global de troca térmica para um tubo limpo é função da temperatura da água de refrigeração e de sua velocidade.

\subsection{Falhas nos Condensadores de Superfície}

As condições de operação do condensador devem ser simplesmente monitoradas a todo tempo, pois não só se olhando a alta pressão de escape pode-se entender a causa disto sem se olhar todas as outras variáveis. As causas mais comuns para falhas nos condensadores são:

1.Alta temperatura da água de entrada para refrigeração ou grandes variações no delta de temperatura entre entrada e saída;

2.Baixa vazão da água de refrigeração;

3.Entupimento dos tubos da água de refrigeração; 
4.Excesso de vazamento de gases não condensáveis para dentro do sistema. Interpretando corretamente o funcionamento do condensador às vistas das possíveis falhas tem se:

5. Quem "cria" o vácuo é o próprio condensador e sua troca térmica;

6. O sistema de vácuo composto pelos ejetores ou pelas bombas de vácuo não são os responsáveis por criar ou manter o vácuo;

7. Os ejetores devem apenas retirar os não condensáveis para que o condensador possa fazer o seu trabalho;

8. O ejetor de partida, como o próprio nome diz, tem a função de tirar todos o ar dentro do condensador para que este possa partir e entrar em operação.

Fica evidente que variações na temperatura da água de refrigeração tem um impacto direto no desempenho do condensador. Mas esta variável é facilmente controlável pois é simples medir temperatura. Quanto à vazão de água já existem medidores de vazão de água comerciais que permitem avaliar corretamente a vazão de água.

Entretanto, no caso da vazão de água, ainda é possível avaliar esta variável pela equação da carga térmica isolando-se a vazão de água:

Onde:

$$
\boldsymbol{h}=\boldsymbol{c p} * \boldsymbol{\rho} * \boldsymbol{q} * \Delta \boldsymbol{t}
$$

$$
\begin{aligned}
& h=\text { coeficiente global de troca } \\
& c p=\text { calor específico } \\
& \rho=\text { densidade da água } \\
& q=\text { vazão de água } \\
& \Delta t=\text { variação de temperatura da água de refrigeração }
\end{aligned}
$$

Então, os maiores problemas são quando se encontra entupimento nos tubos de água de refrigeração ou vazamento de não-condensáveis no sistema. Infelizmente os dois geram o mesmo tipo de efeito - redução no vácuo.

Um possível método para a avaliação destas falhas nos condensadores é utilizar o perfil de temperatura do condensador para avaliar onde está a queda do desempenho.

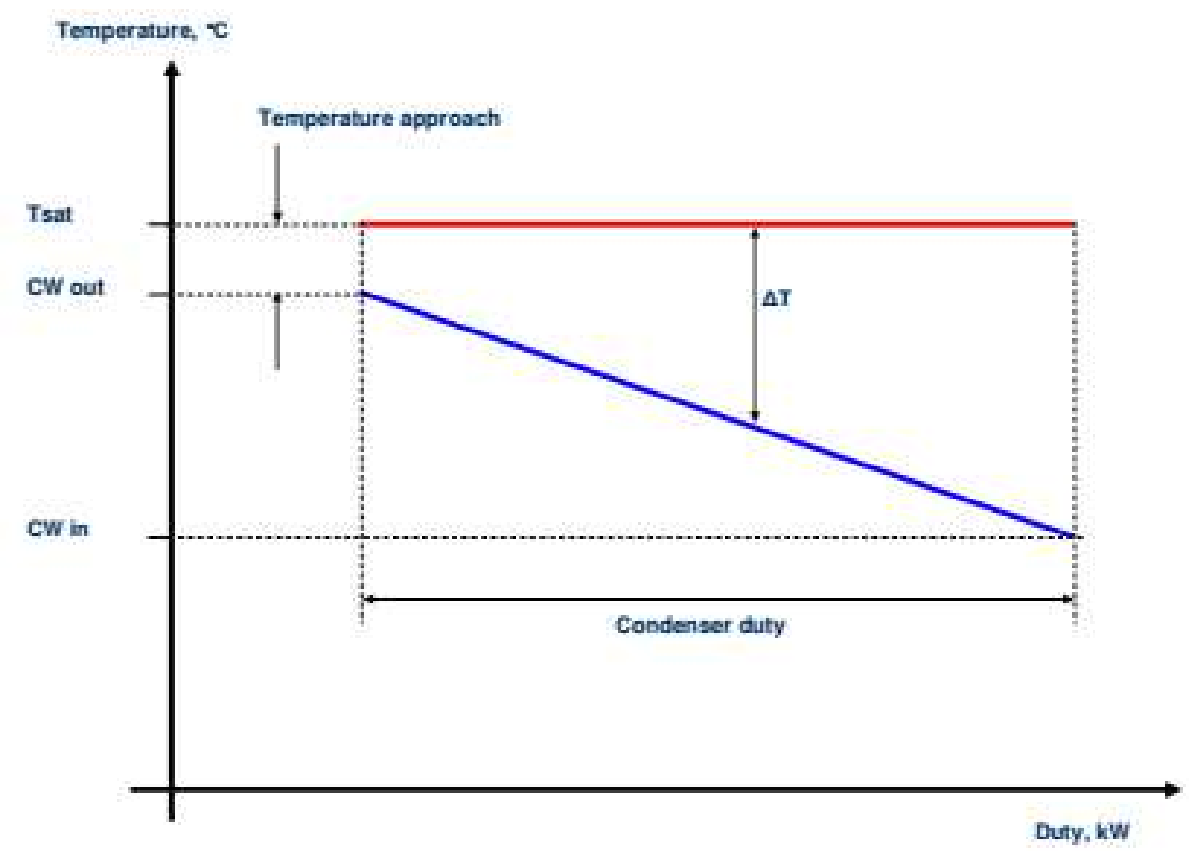

Figura 1. Perfil de temperatura do Condensador. 
Mas para se usar tal método se faz necessário o entendimento de alguns conceitos.

\subsection{Coeficiente Efetivo de Troca Térmica do Condensador}

O condensador de superfície usado no ciclo de rankine tem um coeficiente efetivo de troca térmica $\left(U_{\text {eff }}\right)$ que pode ser calculado pela equação:

Onde:

$$
U_{\text {eff }}=\frac{Q}{A * L M T D}
$$

$L M T D=$ diferença de temperatura média logarítmica

$Q=$ capacidade térmica

$A=$ área de troca do condensador

O cálculo de $U_{\text {eff }}$ é particularmente útil para a avaliação do desempenho do condensador, uma vez que ele permite uma comparação direta entre o valor projetado e um valor que pode ser calculado diretamente dos dados observados em campo.

\subsection{Efeitos do Vazamento de Não-Condensáveis no Sistema}

Se ocorrer um grande vazamento de ar (gás não-condensável) no sistema, superior à capacidade de retirada do sistema de ejetores, tem-se os seguintes efeitos:

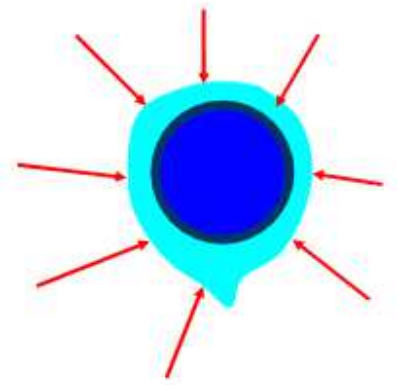

Figura 2. (a) Sem ar no sistema.

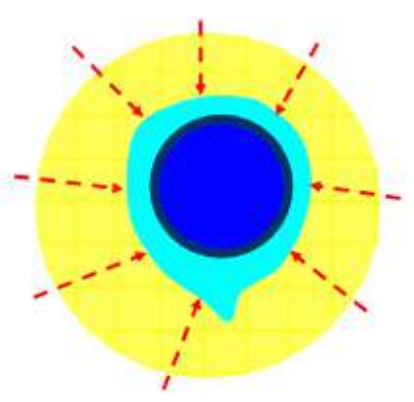

(b) Com entrada de ar.

Sem a presença de não condensáveis, a troca térmica e eficiente e o vapor condensa facilmente. Já com a presença de ar, forma se uma espécie de "cobertor de ar" e o fluxo de vapor torna se difuso sobre os tubos e há a presença de subresfriamento. Portanto, a presença de ar reduz a taxa de transferência de calor.

\section{RESULTADOS E DISCUSSÃO}

\subsection{Análise das Falhas no Condensador}

Fica claro no desenvolvimento do trabalho que, para a avaliação das falhas no sistema de condensado tem se que observar as temperaturas e não a pressão de escape. Para tal, podemos definir alguns parâmetros:

- A redução da vazão de água pode ser percebida pelo aumento no diferencial de temperatura da água de resfriamento, pois a água permanece mais tempo dentro do condensador;

- Os entupimentos podem ser avaliados pela Aproximação da Temperatura de Saturação na Figura 1, já que há um aumento da distância entre a temperatura de saturação e a temperatura da saída da água de refrigeração; 
- Já o ingresso de ar pode ser avaliado pela Aproximação da Temperatura de Saturação e pelo aumento do $\Delta \mathrm{T}$ entre a temperatura de saturação e a temperatura de condensado.

A tabela a seguir mostra os cálculos para esta metodologia:

Tabela 1. Cálculos do Condensador

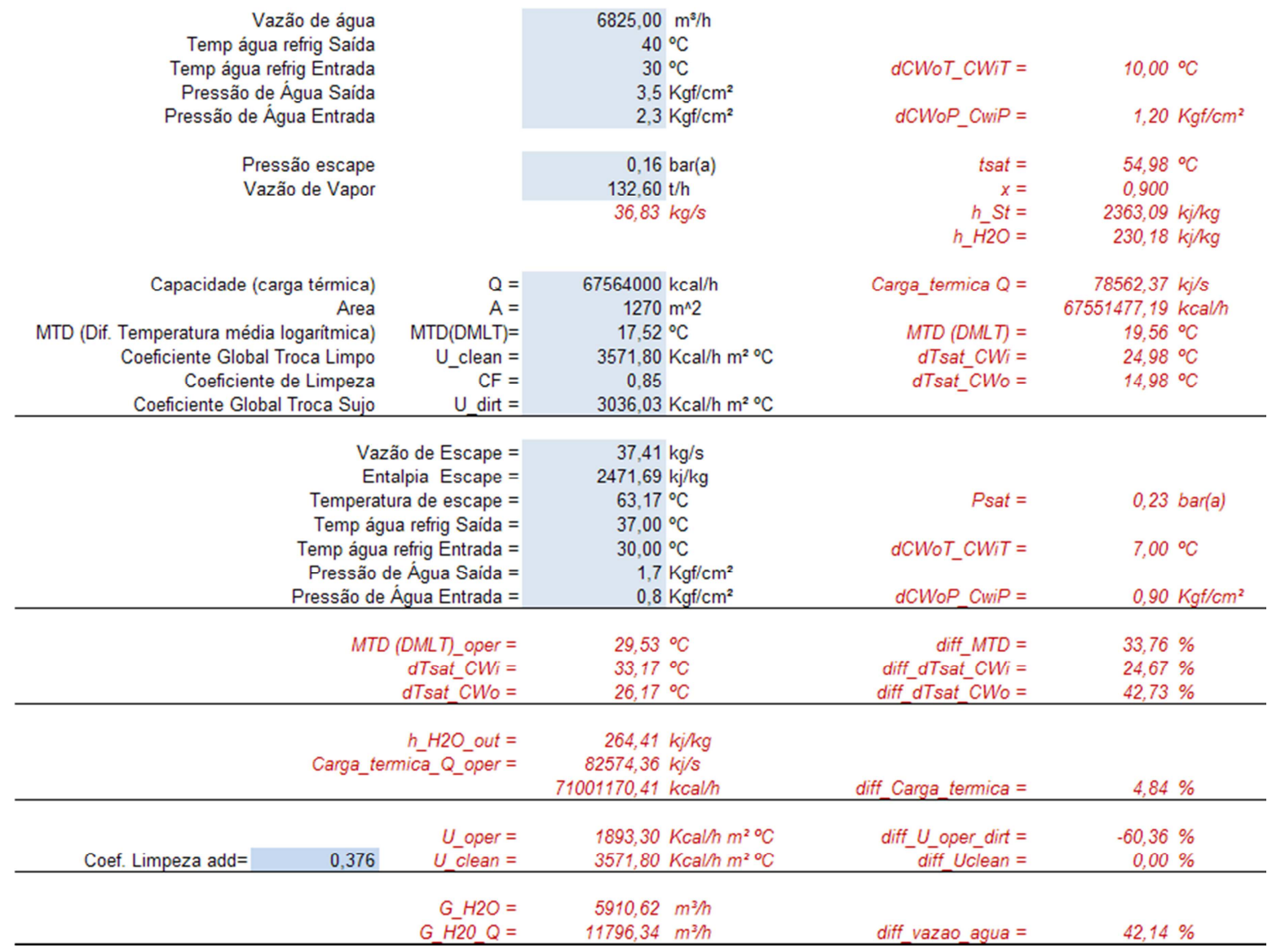

Pela avaliação dos resultados da Tabela 1, pode-se notar que há uma queda do coeficiente global de troca na ordem de $60 \%$ além de uma variação negativa no $\Delta t$ de apenas $7^{\circ} \mathrm{C}$ onde deveríamos ter $10^{\circ} \mathrm{C}$, há um afastamento entre a temperatura de saturação e a temperatura da água de saída em $40 \%$ para uma diferença na carga térmica de apenas $4 \%$.

Com estes resultados a partir da metodologia proposta é possível avaliar que existem problemas de sujidade nos tubos de água de refrigeração e um possível vazamento de ar neste condensador.

\subsection{Impactos para a Geração de Energia}

Em uma situação de perda de pressão e temperatura no escape de uma máquina de condensação, tem se um impacto direto na geração de energia pela perda de eficiência e pela diminuição direta da variação de entalpia na turbina. Este é um custo considerável e que deve ser levado em conta no momento de se preparar uma intervenção em um condensador. Por exemplo, para o perfil de pressão e temperatura do condensador mostrado na tabela 1, o desempenho da turbina é apresentado na tabela a seguir. 
Tabela 2. Avaliações do turbogerador.

Potência ativa gerador

Vazão vapor de admissão

Pressão vapor de admissão

Temperatura vapor de admissão
$29885,00 \mathrm{~kW}$

$143,90 \mathrm{t} / \mathrm{h}$

65,16 bar

$503,05^{\circ} \mathrm{C}$
$39,97 \mathrm{~kg} / \mathrm{s}$

66,18 bara

Entalpia de admissão

Pressão da câmara da roda

Vazão de vapor de extração

Pressão vapor de extração

Temperatura vapor de extração

Temperatura de extração calculada

Entalpia de extração Potência mecânica turbina alta

Pressão de câmara da roda calculada

39,87 bar

ho $=$

$3423,09 \mathrm{kj} / \mathrm{kg}$

\begin{tabular}{|c|c|}
\hline 39,87 bar & 40,89 bara \\
\hline$P_{C r}=$ & 42,81 bara \\
\hline $106,49 \mathrm{t} / \mathrm{h}$ & $29,58 \mathrm{~m} / \mathrm{s}$ \\
\hline 2,53 bar & 3,54 bara \\
\hline $139,39^{\circ} \mathrm{C}$ & \\
\hline$T \_c a l c \_e f f-H P=$ & $162,97^{\circ} \mathrm{C}$ \\
\hline$h 1=$ & $2732,79 \mathrm{kj} / \mathrm{kg}$ \\
\hline pot hp $=$ & $27592,79 \mathrm{~kW}$ \\
\hline
\end{tabular}

Vazão vapor de escape

Pressão vapor de escape

Temperatura vapor de escape

\begin{tabular}{|c|c|c|c|}
\hline & $\begin{array}{r}(\text { Entalpia psat,X) } \\
(\text { Entalpia PIT-30_10_4,X) } \\
\text { Potência mecânica turbina baixa }\end{array}$ & $\begin{array}{r}h 2= \\
h 2^{\prime}= \\
\operatorname{pot} 1 \rho=\end{array}$ & $\begin{array}{ll}2377,08 & \mathrm{kj} / \mathrm{kg} \\
2377,08 \mathrm{kj} / \mathrm{kg} \\
3696,39 \mathrm{~kW}\end{array}$ \\
\hline & & $\begin{array}{r}\text { Eff HP }= \\
\text { Eff LP }= \\
\text { Eff STG }= \\
\text { Eff Redutor }= \\
\text { Eff Gerador }= \\
\text { Perdas mecânicas }=\end{array}$ & $\begin{array}{r}0,87 \\
0,79 \\
0,86 \\
0,980 \\
0,985 \\
0,01 \\
318,45 \mathrm{~kW}\end{array}$ \\
\hline (para h0;h1;h2) & $\begin{array}{r}\text { Potência mecânica na turbina } \\
\text { Potência gerador }\end{array}$ & $\begin{array}{r}\text { pot_mec }= \\
\text { pot_ger }= \\
\text { Diff }=\end{array}$ & $\begin{array}{c}31289,18 \mathrm{~kW} \\
29885,00 \mathrm{~kW} \\
0,00 \%\end{array}$ \\
\hline
\end{tabular}

Como é conhecido que há um problema no condensador, foi feita uma simulação para as mesmas condições de vapor de admissão e extração, mas considerando-se a temperatura e o vácuo de projeto. Esta simulação apresentou um ganho na ordem $1,45 \%$ na potência gerada pelo conjunto.

Esta simulação pode ser vista na tabela 3. 
Tabela 3. Simulações para um vácuo de projeto.

Potência ativa gerador Vazão vapor de admissão

Pressão vapor de admissão

Temperatura vapor de admissão
$29885,00 \mathrm{~kW}$

$143,90 \mathrm{t} / \mathrm{h}$

65,16 bar

$503,05^{\circ} \mathrm{C}$
$39,97 \mathrm{~kg} / \mathrm{s}$

66,18 bara

ho $=3423,09 \mathrm{kj} / \mathrm{kg}$

Pressão da câmara da roda
Vressão de câmara da roda calculada
$\begin{aligned} & \text { Vazão de vapor de extração } \\ & \text { Pressão vapor de extração } \\ & \text { Temperatura vapor de extração } \\ & \text { Temperatura de extração calculada } \\ & \text { Entalpia de extração } \\ & \text { Potência mecânica turbina alta }\end{aligned}$

Vazão vapor de escape

Pressão vapor de escape

Temperatura vapor de escape

Entalpia de admissão

\begin{tabular}{|cc}
39,87 bar & 40,89 bara \\
Pcr $=$ & $42,81 \mathrm{bara}$ \\
$106,49 \mathrm{t} / \mathrm{h}$ & $29,58 \mathrm{~m} / \mathrm{s}$ \\
$2,53 \mathrm{bar}$ & $3,54 \mathrm{bara}$ \\
$139,39{ }^{\circ} \mathrm{C}$ & \\
$T_{-}$calc_eff-HP $=$ & $162,97^{\circ} \mathrm{C}$ \\
$h 1=$ & $2732,79 \mathrm{kj} / \mathrm{kg}$ \\
pot $h p=$ & $27592,79 \mathrm{~kW}$ \\
\hline
\end{tabular}

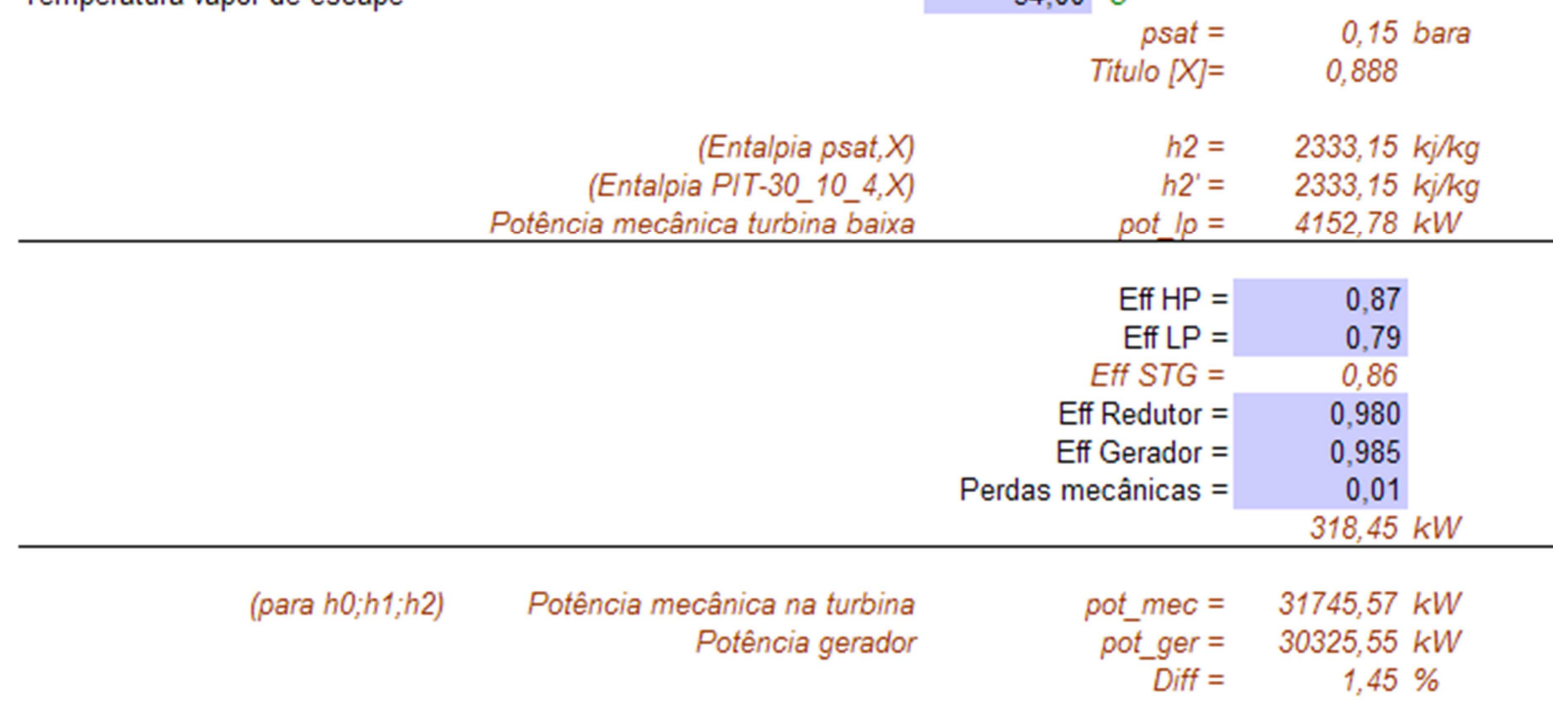

A diferença na energia gerada foi de aproximadamente $0,44 \mathrm{MW}$ e tomando-se um valor de mercado para o $\mathrm{MW} / \mathrm{h}$ de $\mathrm{R} \$ 250,00$, em uma campanha de operação de 350 dias/ano (considerando-se 15 dias de parada para revisões e manutenções preventivas e/ou corretivas), a queda no desempenho do condensador irá representar economicamente:

$$
\$_{\text {cond. }}=0,44 * 24 h * 350 * R \$ 250,00=R \$ 924.000,00
$$

Este valor justifica a manutenção no condensador e mostra a real necessidade que este equipamento deve ter nos programas de manutenção.

\section{CONCLUSÃO}

Um ganho de $1,45 \%$ na potência gerada em uma turbina justifica a importância do investimento em rotinas adequadas de monitoramento e manutenção nos condensadores de vapor instalados em turbogeradores.

A avaliação de desempenho destes equipamentos não é uma rotina complicada e não exige investimentos de grande aporte em monitoramento. Entretanto, a 
engenharia envolvida com a manutenção e operação destes equipamentos deve ser bem pensada para obter os resultados adequados e esperados.

\section{BIBLIOGRAFIA}

1 "Operation and Maintenance of Steam Surface Condensers." Fossil Plant News. Electric Power Research Institute, Spring 1988, Issue \# 4.

2 Albert Bursik \& Hans-Gunter Seipp, "Condenser tube failures in water-cooled condensers with copper-based alloys"PPChem,

3 "Troubleshooting Steam Surface Condensers" Progressive Thermal Engineering, HTS Forum 12 September 2012. 